\title{
FORÇA MUSCULAR E FUNCIONALIDADE DO JOELHO DE IDOSAS PRATICANTES DE HIDROGINÁSTICA
}

\author{
Daniel Vicentini de Oliveira ${ }^{1}$, Adriele Tarine dos Santos ${ }^{2}$, Mateus Dias Antunes ${ }^{3}$, José Roberto Andrade do \\ Nascimento Júnior ${ }^{4}$, Sônia Maria Marques Gomes Bertolini ${ }^{5}$
}

\begin{abstract}
RESUMO: Este estudo teve como objetivo relacionar a força muscular de membros inferiores com a funcionalidade do joelho de idosas praticantes de hidroginástica. Trata-se se de um estudo transversal realizado entre junho e setembro de 2016 na cidade de Maringá no Paraná. A amostra foi composta por 147 idosas praticantes de hidroginástica. Foi utilizado o teste de levantar e sentar da cadeira por 30 segundos e o questionário Cincinnati. Observou-se que as idosas apresentaram nível fraco de força muscular de membro inferior [Md = 13 (Q1 = 11; Q3 $=16)]$. Verificou-se correlação significativa $(p=0,001)$ e moderada $(r=0,68)$ entre a força muscular de membros inferiores e a funcionalidade do joelho. A correlação moderada entre a força muscular de membros inferiores e a funcionalidade do joelho das idosas sugere uma importante associação entre essas variáveis.

DESCRITORES: Atividade motora; Envelhecimento; Aptidão física; Promoção da saúde; Gerontologia.
\end{abstract}

\section{MUSCLE STRENGTH AND KNEE FUNCTIONALITY OF ELDERLY WOMEN PRACTICING WATER AEROBICS}

\begin{abstract}
The objective in this study was to relate the lower limb muscle strength with the knee functionality of elderly women practicing water aerobics. A cross-sectional study was developed between June and September 2016 in the city of Maringá, state of Paraná, Brazil. The sample consisted of 147 elderly women practicing water aerobics. The 30-second chair stand test and the Cincinnati questionnaire were used. It was observed that the elderly women presented low levels of lower limb muscle strength [Md $=13(\mathrm{Q} 1=11 ; \mathrm{Q} 3=16)]$. A significant $(\mathrm{p}=0.001)$ and moderate $(r=0.68)$ correlation was found between lower limb muscle strength and knee functionality. The moderate correlation between the lower limb muscle strength and knee functionality of the elderly women suggests an important association between these variables.

DESCRIPTORS: Motor activity; Aging; Physical aptitude; Health promotion; Gerontology.
\end{abstract}

\section{FUERZA MUSCULAR Y FUNCIONALIDAD DE LA RODILLA DE ANCIANAS PRACTICANTES DE AQUAGYM}

RESUMEN: El objetivo de este estudio fue relacionar la fuerza muscular de miembros inferiores con la funcionalidad de la rodilla de ancianas practicantes de aquagym. Se trata de un estudio trasversal desarrollado entre junio y septiembre de 2016 en la ciudad de Maringá, estado de Paraná, Brasil. La muestra incluyó a 147 ancianas practicantes de aquagym. Fue utilizado la prueba 30-second chair stand y el cuestionario Cincinnati. Se observó que las ancianas presentaron nivel débil de fuerza muscular de miembro inferior $[\mathrm{Md}=13(\mathrm{Q} 1=11 ; \mathrm{Q} 3=16)]$. Fue verificada correlación significativa $(\mathrm{p}=0,001)$ y moderada $(r=0,68)$ entre la fuerza muscular de miembros inferiores y la funcionalidad de la rodilla. La correlación moderada entre la fuerza muscular de miembros inferiores y la funcionalidad de la rodilla de las ancianas sugiere una asociación importante entre esas variables.

DESCRIPTORES: Actividad motora; Envejecimiento; Aptitud física; Promoción de la salud; Gerontología.

${ }^{1}$ Educador físico e Fisioterapeuta. Doutorando em Gerontologia pela Universidade Estadual de Campinas. Campinas, SP, Brasil.

${ }^{2}$ Educadora física. Faculdade Metropolitana de Maringá. Maringá, PR, Brasil.

${ }^{3}$ Fisioterapeuta. Mestrando em Promoção da Saúde pelo Centro Universitário Cesumar. Maringá, PR, Brasil.

${ }^{4}$ Educador físico. Doutor em Educação física. Docente da Universidade Federal do Vale do São Francisco. Petrolina, PE, Brasil. ${ }^{5}$ Fisioterapeuta. Doutora em Ciências Morfofuncionais. Centro Universitário de Maringá. Maringá, PR, Brasil. 


\section{INTRODUÇÃO}

O envelhecimento humano é um processo caracterizado por diversas alterações fisiológicas, morfológicas, psicológicas e sociais que ocorrem no organismo de forma natural. Pode ser conceituado como um processo dinâmico, universal, progressivo e individual ${ }^{(1)}$. A idade avançada desencadeia alterações celulares, musculares e funcionais, reduzindo a capacidade de manutenção da homeostasia, e consequentemente maior disposição às doenças ${ }^{(2)}$.

Dentre as diversas alterações que ocorrem com o processo de envelhecimento, as do aparelho locomotor merecem destaque, principalmente por possuírem relação com a fragilidade e funcionalidade, como a diminuição da massa magra, denominada sarcopenia ${ }^{(3)}$. A perda de massa magra está relacionada à perda da força no envelhecimento, no entanto há outra denominação que alguns autores ${ }^{(4-5)}$ propõem para definir a perda específica da força, chamada de dinapenia ${ }^{(6)}$. Os mesmos autores relatam que a perda de massa muscular explica apenas $10 \%$ da perda de força e da incapacidade encontrada em indivíduos idosos. Em um estudo ${ }^{(7)}$ realizado com 56 idosas, com média de idade de 62.5 \pm 5.4 anos, também apontou que existe relação entre massa muscular e força muscular na performance física de indivíduos idosos, porém a força muscular é melhor preditora no desempenho físico do que a massa muscular.

A diminuição da força dos membros inferiores afeta a mobilidade funcional, aumentando a propensão de quedas e influenciando na marcha, sendo essa um fator indicador do risco de perda de autonomia e independência desses indivíduos ${ }^{(8)}$. Sabe-se que a força muscular é de grande importância na vida de um idoso, pois as atividades diárias requerem a mesma ${ }^{(9)}$. As realizações de inúmeras tarefas cotidianas dependem, em grande parte, da força muscular dos membros inferiores ${ }^{(10-11)}$.

Quando o idoso apresenta uma capacidade funcional inadequada, ele passa a ter dificuldades em realizar tais atividades, muitas vezes devido a dores no joelho, que consequentemente segue de uma musculatura dos membros inferiores enfraquecida ${ }^{(12-13)}$. Diante destas premissas, destacase a importância dos exercícios físicos nesta fase da vida como importante medida de prevenção e tratamento de do aparelho locomotor e de outras doenças crônico-degenerativas ${ }^{(14)}$.

Os exercícios físicos promovem segurança nas realizações das Atividades de vida diária (AVDs), garantindo o desempenho funcional e, consequentemente, maior independência e autonomia. Estudo $^{(15)}$ realizado com 44 idosos moradores da comunidade, com média de idade de 88,75 $\pm 4,05$ anos, destacou a importância de exercícios físicos, que durante o processo de envelhecimento, proporcionam uma série de efeitos benéficos na independência funcional, o que vem acarretar uma melhora na qualidade de vida e nas AVDs. Dentre tantas modalidades e práticas adequadas ao idoso, uma em especial, que é o foco deste estudo, é a hidroginástica.

Um grande número de idosos busca a hidroginástica com o intuito de manter-se ativo ${ }^{(16)}$, devido à praticidade e vantagens que as propriedades físicas da água promovem, auxiliando na movimentação das articulações, ganho de flexibilidade, baixo impacto e ganho de força muscular, dentre outros benefícios $^{(17)}$. Posto isso, o presente estudo teve como objetivo relacionar a força muscular de membros inferiores com a funcionalidade do joelho de idosas praticantes de hidroginástica.

\section{METODOLOGIA}

A amostra não probabilística, escolhida por conveniência, foi composta por 147 idosas praticantes de hidroginástica em academias do município de Maringá, estado do Paraná (PR), que ofereciam essa modalidade. A coleta de dados foi realizada após a autorização das nove academias que oferecem esta modalidade no município de Maringá-PR, no período de junho a agosto de 2016.

Foram incluídas idosas do sexo feminino, com 60 anos ou mais, praticantes exclusivamente de hidroginástica há pelo menos três meses, com frequência de duas vezes na semana. Foram excluídas idosas praticantes de mais de uma modalidade de exercícios (além da hidroginástica), e com déficits auditivos e visuais que impedissem a realização dos questionários. Idosas que apresentavam prótese de joelho e/ou quadril, e idosas que utilizavam algum acessório para a marcha também foram excluídas. 
Como instrumento de medida, foi utilizado um questionário sociodemográfico, elaborado pelos próprios autores, com questões como idade, faixa etária (60 a 70 anos, 71 anos ou mais), renda mensal em salário mínimo (SM) (R\$ 880,00, conforme SM de 2016), escolaridade, raça, aposentadoria, situação ocupacional, situação conjugal, tempo de prática da hidroginástica, frequência semanal, medicamentos utilizados, percepção de saúde, motivos que levaram à prática da hidroginástica, tabagismo, presença de dores durante a prática de hidroginástica.

Para a funcionalidade do joelho, foi aplicado o questionário Cincinatti, validado na língua portuguesa, que divide em oito questões e atribui notas a diversos itens relacionados à dor, falseio e capacidade de deslocamento, sendo o joelho normal contemplado com 100 pontos. Assim, é possível verificar o quanto o joelho acometido dificulta a realização de atividades de rotina do paciente por meio dessa pontuação quando a soma total é mais próximo de 0 , e quanto mais próximo de 100, obtêm joelho normal sem limitações ${ }^{(18)}$.

Também foi realizado o Teste de levantar e sentar da cadeira (LSC) por 30 segundos adquirido do protocolo da avaliação funcional para idosos de Rikli e Jones validado para a população brasileira, que tem por objetivo avaliar a força e resistência muscular de membros inferiores. O teste foi executado em uma cadeira de 43 centímetros de altura, sem apoio de membro superior, com encosto, encostada na parede. No teste, o avaliado inicia sentado com os pés no chão e os braços cruzados ao peito. Ao sinal do avaliador o participante ergue-se e fica totalmente em pé e então retorna à posição sentada. As idosas foram encorajadas a completar o máximo possível dessa ação em 30 segundos e a pontuação é obtida pelo número total de execuções corretas. O teste foi realizado três vezes, sendo considerado apenas o teste com melhor resultado ${ }^{(19)}$.

Trata-se se de um estudo quantitativo, observacional de delineamento transversal. Este estudo foi aprovado pelo Comitê de ética em pesquisa com seres humanos do Centro Universitário de Maringá, por meio do parecer número 1.769.637. Inicialmente, as idosas foram informadas quanto à justificativa e objetivos do trabalho e, aquelas que aceitaram, assinaram o Termo de consentimento livre e esclarecido. Os instrumentos de pesquisa foram coletados nas próprias academias sempre antes da prática de hidroginástica pelas idosas segundo os horários pré-verificados.

Para a análise dos dados, utilizou-se frequência e percentual para as variáveis categóricas. Para as variáveis numéricas, inicialmente foi verificada a normalidade dos dados por meio do teste de Kolmogorov-Smirnov. Como os dados não apresentaram distribuição normal, foram utilizadas Mediana (Md) e Quartis (Q1; Q3) para a caracterização dos resultados. Na comparação da força muscular de membros inferiores e da funcionalidade do joelho em função da faixa etária (até 70 anos e mais de 70 anos), foi utilizado o teste " $U$ " de Mann-Whitney. Para verificar a correlação entre a força muscular de membros inferiores e a funcionalidade do joelho, utilizou-se o coeficiente de correlação de Spearman. Considerou-se um nível de significância de $p<0,05$.

\section{RESULTADOS}

As idosas apresentaram média de idade de 69,4 \pm 6,9 anos. Analisando as características da amostra, verificou-se que 88 (59,9\%) tinham idade entre 60 e 70 anos, 128 (87,1\%) eram da raça branca, $116(78,9 \%)$ estavam aposentadas, 123 (83,7\%) tinham renda mensal de mais de dois salários mínimos, e 132 (89,8\%) eram ativas ocupacionalmente. Observou-se também que 74 idosas (50,3\%) eram casadas (Tabela 1).

Tabela 1 - Distribuição de frequência do perfil sócio demográfico das idosas praticantes de hidroginástica. Maringá, PR, Brasil, 2016 (continua)

\begin{tabular}{lll} 
VARIÁVEIS & $\mathbf{n}$ & $\mathbf{\%}$ \\
\hline Estado civil & & \\
\hline Casada & 74 & 50,3 \\
\hline Não casada & 73 & 49,7 \\
\hline
\end{tabular}




\begin{tabular}{lcc}
\hline Faixa Etária & & \\
\hline 60 a 70 anos & 88 & 59,9 \\
\hline 71 a 80 anos & 52 & 35,3 \\
\hline Mais de 80 anos & 4,8 \\
\hline Renda mensal & 24 & \\
\hline Até 2 salários mínimos & 56 & 36,3 \\
\hline 2 a 3 salários mínimos & 67 & 45,6 \\
\hline Mais de 3 salários mínimos & & \\
\hline Escolaridade & 9 & 6,1 \\
\hline Analfabeto & 27 & 18,4 \\
\hline Fundamental Incompleto & 41 & 27,9 \\
\hline Fundamental Completo & 70 & 47,6 \\
\hline Médio Completo/Superior & & \\
\hline Raça & 128 & 87,1 \\
\hline Branca & 14 & 9,5 \\
\hline Caucasiana/Negra & 5 & 3,4 \\
\hline Asiática & & \\
\hline Aposentadoria & 116 & 78,9 \\
\hline Sim & 31 & 21,1 \\
\hline Não & 132 & 89,8 \\
\hline Situação Ocupacional & 15 & 10,2 \\
\hline Ativo & & \\
\hline Não-ativo & & \\
\hline
\end{tabular}

Já em relação ao perfil de saúde e atividade física das idosas praticantes de hidroginástica (Tabela 2), verificou-se que a maioria das idosas praticavam hidroginástica há mais de cinco anos ( $\mathrm{n}=72 / 49 \%)$, tomavam 3 ou mais medicamentos de forma regular $(n=55 / 37,4 \%)$ e não sentiam dor durante a prática da hidroginástica ( $n=137 / 93,2 \%)$. Em relação à força muscular de membro inferior, observou-se que apenas nove $(6,1 \%)$ idosas apresentaram nível muito bom no teste LSC. Em relação ao número de repetições neste teste, observou-se que as idosas apresentaram nível fraco de força muscular [Md = $13(\mathrm{Q} 1=11 ; \mathrm{Q} 3=16)]$.

Tabela 2 - Distribuição de frequência do perfil de saúde e atividade física idosas praticantes de hidroginástica. Maringá, PR, Brasil, 2016 (continua)

\begin{tabular}{lcc} 
VARIÁVEIS & $\mathbf{n}$ & $\mathbf{\%}$ \\
\hline Tempo de prática de atividade física & & \\
\hline 3 meses a 1 ano & 15 & 10,2 \\
\hline 1,1 a 3 anos & 26 & 17,7 \\
\hline 3,1 a 5 anos & 34 & 23,1 \\
\hline Mais de 5 anos & 72 & 49 \\
\hline Uso de Medicamento & & \\
\hline Não utiliza & 14 & 9,5 \\
\hline 1 medicamento & 27 & 18,4 \\
\hline 2 medicamentos & 51 & 34,7 \\
\hline 3 ou mais medicamentos & 55 & 37,4 \\
\hline Sente dor no joelho durante a prática & & \\
\hline Não & 137 & 93,2 \\
\hline Sim & 10 & 6,8 \\
\hline
\end{tabular}




\begin{tabular}{lccc}
\hline LSC (Força Muscular de membro inferior) & & \\
\hline Muito Fraco & 48 & 32,7 \\
\hline Fraco & 36 & 24,5 \\
\hline Regular & 35 & 23,8 \\
\hline Bom & 19 & 12,9 \\
\hline Muito Bom & 9 & 6,1
\end{tabular}

LSC: Teste Levantar e sentar na cadeira.

Em relação à funcionalidade do joelho, verificou-se também que as idosas apresentaram boa funcionalidade $[\mathrm{Md}=87(\mathrm{Q} 1=74 ; \mathrm{Q} 3=96)]$.

Ao comparar a força muscular e a funcionalidade do joelho das idosas praticantes de hidroginástica em função da faixa etária (Figura 1), verificou-se diferença significativa tanto na força muscular $(p=$ $0,001)$ quanto na funcionalidade do joelho $(p=0,003)$, evidenciando que as idosas na faixa etária de até 70 anos apresentaram melhor funcionalidade do joelho $(\mathrm{Md}=88,0)$ e força muscular de membros inferiores $(\mathrm{Md}=14,5)$ do que as idosas acima de 70 anos ( $\mathrm{Md}=83$ e 12, respectivamente).

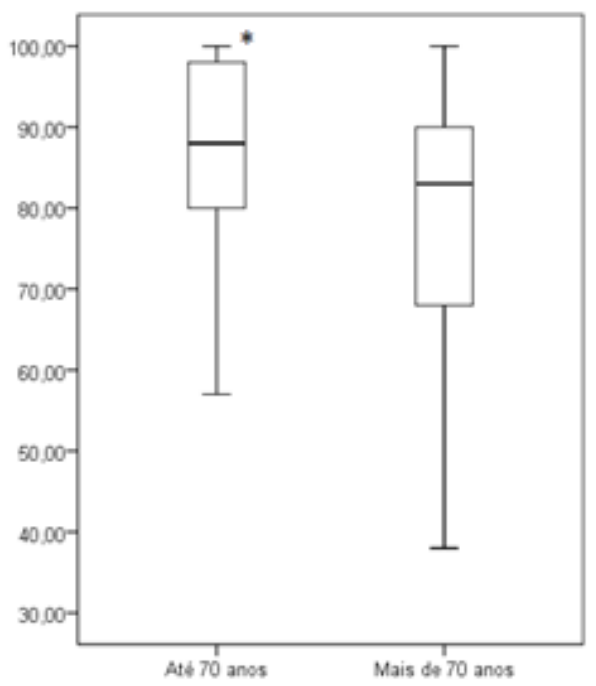

Funcionalidade do Joelho

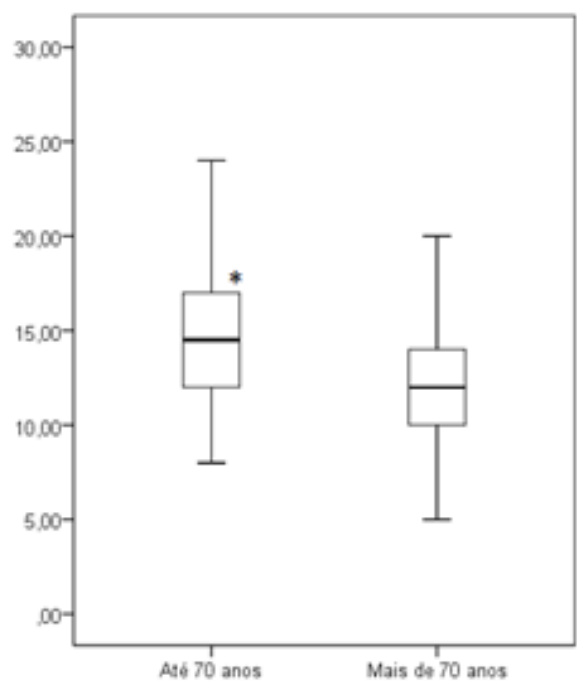

Força Muscular

Figura 1 - Comparação da força muscular e da funcionalidade do joelho das idosas praticantes de hidroginástica em função da faixa etária. *Diferença significativa $(p<0,05)$ - Teste "U" de Mann-Whitney. Maringá, PR, Brasil, 2016

Verificou-se correlação significativa $(p=0,001)$ e moderada $(r=0,68)$ entre a força muscular de membros inferiores (Teste LSC) e a funcionalidade do joelho (Questionário Cincinatti), indicando que, quanto maior a força muscular, melhor a funcionalidade do joelho, ou vice-versa (Figura 2). 


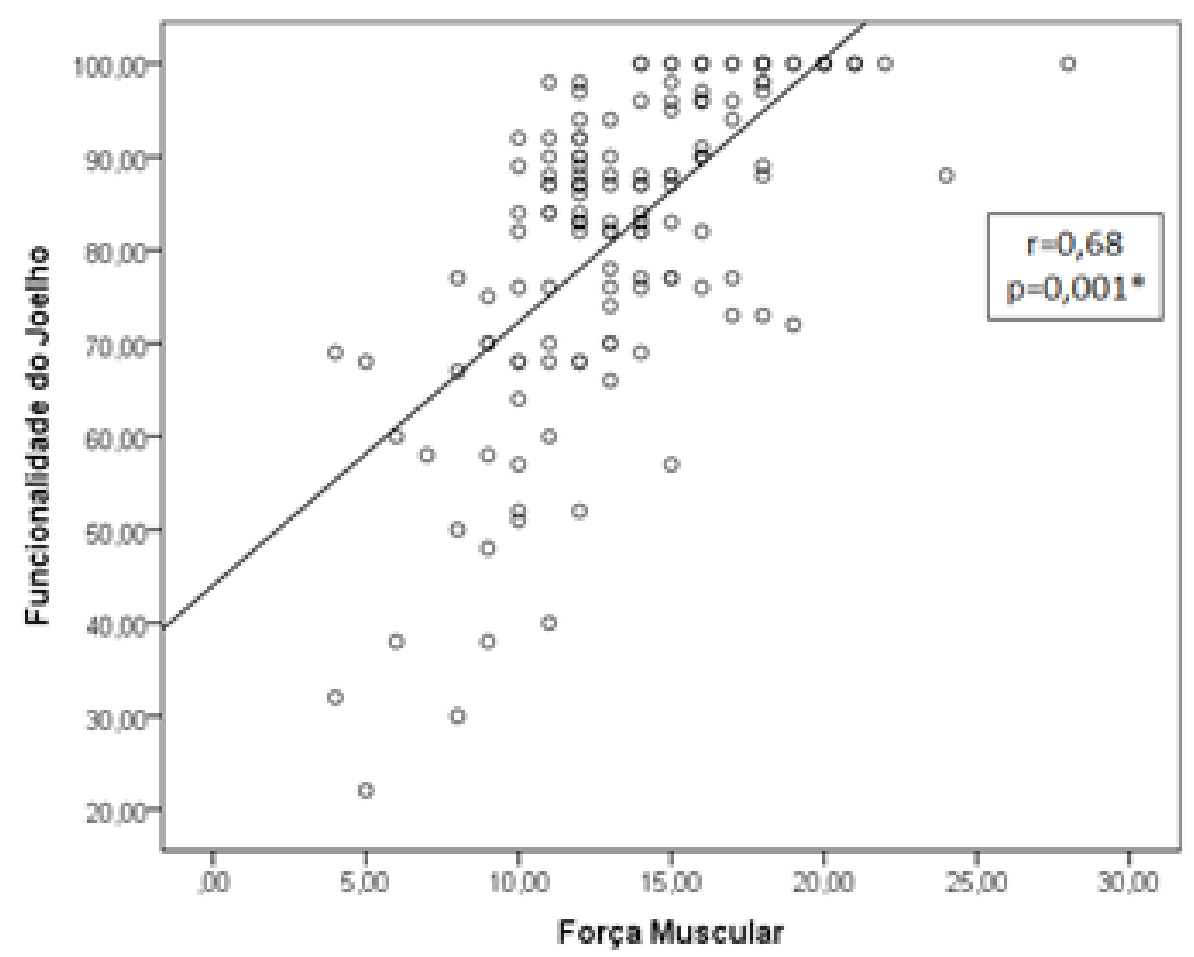

Figura 2 - Correlação da força muscular com a funcionalidade do joelho das idosas praticantes de hidroginástica. *Correlação Significativa ( $p<0,05)$ - Correlação de Spearman. Maringá, PR, Brasil, 2016

\section{- DISCUSSÃO}

Este estudo identificou que a maioria das idosas apresentou força muscular de membro inferior fraca ou muito fraca no teste de levantar e sentar da cadeira. A força muscular de membros inferiores mostrou-se correlacionada moderadamente à funcionalidade do joelho das idosas.

A avaliação da força e da função muscular é fundamental no processo de envelhecimento, devido estar relacionada à autonomia do idoso, pois as atividades cotidianas necessitam de certos níveis de força para executá-las ${ }^{(20)}$. O mesmo autor conclui em seu estudo que a manutenção de bons níveis de força é necessária para o desempenho satisfatório nas tarefas diárias, sejam estas atividades profissionais ou cotidianas, e para a manutenção de uma boa qualidade de vida independente da idade.

A força muscular, que pode ser definida como a capacidade de o músculo gerar tensão como também sua qualidade em determinado movimento, atinge seu pico por volta dos trinta anos de idade, a partir disso iniciam-se os declínios musculares. Após os 60 anos de idade, a perda de força muscular se agrava, e é responsável pelos consideráveis déficits motores observados em indivíduos nessa faixa etária ${ }^{(21-22)}$. O declínio da força muscular é mais acentuada a partir dos 60 anos ${ }^{(23)}$, principalmente nas mulheres e especificamente nos membros inferiores, pois está associada à diminuição no nível de atividade física, fatores nutricionais, hormonais, endócrinos e neurológicos ${ }^{(24)}$.

Ademais, era esperado que as participantes da pesquisa apresentassem níveis de força significativamente melhores dos encontrados, pelo fato da maioria das idosas praticarem a hidroginástica no mínimo três meses. Estudo ${ }^{(25)}$ realizado com 16 mulheres em Foz do Iguaçu aponta que a melhoria da quantidade de força em idosos ocorre de forma relativamente rápida, podendo ser identificada em média de dois meses.

Em outro estudo ${ }^{(26)}$ em Fortaleza, 26 idosas que frequentavam o Serviço Social do Comércio, com idade entre 60 e 80 anos, relatam que na hidroginástica deve-se vencer a resistência da água, os exercícios realizados nesse meio exigem mais força que em solo. No entanto, a resistência dependente da velocidade e do formato da parte que se move, para exercer certa tensão muscular. A escolha do teste aplicado tem a vantagem de exigir uma movimentação contínua, similar àquela exigida pela modalidade, de modo que os dados obtidos podem contribuir para uma estimativa mais precisa da 
força de membros inferiores.

Os resultados encontrados na comparação entre as diferentes faixas etárias corroboram os achados da literatura. Verificou-se diferença estatisticamente significativa entre as idosas de 60 a 70 anos e 71 ou mais, indicando que as idosas mais velhas possuem menos força muscular do que as mais novas. Sendo confirmada a tendência das médias a diminuírem com o avançar da idade, em função da perda tanto de força quanto de massa muscular. Estudo ${ }^{(27)}$ realizado com 59 idosas, sendo um grupo praticante de hidroginástica e o outro de ginástica no mínimo seis meses, não encontrou diferença significativas nos índices de força de membros inferiores ao realizar o mesmo teste de sentar e levantes em 30 segundos em ambas classificações das faixas etárias.

Outros autores ${ }^{(28)}$ também encontraram resultados significativos na força de membros inferiores de 21 mulheres idosas submetidas a um trabalho de hidroginástica, com frequência de duas vezes por semana, durante 72 semanas em Florianópolis. Já outro estudo ${ }^{(29)}$ realizado em Ipatinga, com 26 idosas com média de idade de $71 \pm 5,7$ anos, que utilizaram o mesmo teste para avaliar a força de membros inferiores de idosas praticantes de hidroginástica, os resultados alcançados pela amostra foram superiores em relação aos dados referenciais de outro estudo ${ }^{(9)}$ realizado no Ceará que utilizaram o teste de "sentar-levantar" em 30 mulheres praticantes de hidroginástica e 30 mulheres de grupo controle. As praticantes realizavam hidroginástica duas vezes por semana, durante um período de três meses. O pós-teste das praticantes indicou aumento na força de membros inferiores, quando comparados ao pré-teste do mesmo grupo e também quando comparados ao pós-teste do grupo controle.

No presente estudo, a idosas apresentaram boa funcionalidade no joelho mesmo encontrando alteração na força muscular dos membros inferiores, visto que há uma relação entre os músculos envolvidos na articulação do joelho. Os extensores e flexores do joelho estabilizam a articulação, e o declínio da força desses grupos musculares reduz a capacidade de proteger esta articulação ${ }^{(3)}$.

Com o decorrer da idade, a elasticidade e estabilidade dos músculos, tendões e ligamentos se deterioram, a área transversal dos músculos torna se menor pela atrofia muscular e a massa muscular diminui em proporção ao peso do corpo, o que leva a uma redução da força muscular ${ }^{(20)}$. Estudos prévios fornecem evidência de que a força dos extensores do joelho, quando preservada, está associada a um melhor desempenho nas atividades da vida diária e até mesmo maior prevenção de quedas ${ }^{(4)}$.

Este estudo apresenta uma relevante importância pois a funcionalidade do joelho é essencial para a realização das atividades de vida diária do idoso que melhoram a qualidade de vida, bem como a prática regular de atividade física, além dos benefícios fisiológicos, são consideradas como práticas e espaços que promovem a saúde do idoso. Isso evidencia que os profissionais da área da saúde devem atuar de maneira interdisciplinar a partir desses resultados para propor estratégias e ações de saúde.

Aponta-se como limitações deste estudo a amostra composta apenas por idosas do sexo feminino, fato este que impediu a comparação da força muscular de membro inferior e funcionalidade do joelho em relação ao sexo; idosas apenas do município de Maringá, no estado do Paraná, o que não representa a população idosa praticante de hidroginástica de forma geral, e sim de um único local.

\section{- CONCLUSÃO}

Os achados do presente estudo indicam fragilidade das idosas praticantes de hidroginástica em relação à força muscular. A correlação moderada entre a força muscular de membros inferiores e a funcionalidade do joelho das idosas sugere uma importante associação entre essas variáveis e indicam, por sua vez, a necessidade de se intensificar o trabalho dos grupos musculares que atuam na referida articulação.

\section{AGRADECIMENTOS}

À Coordenação de Aperfeiçoamento de Pessoal de Nível Superior e Instituto Cesumar de Ciência, Tecnologia e Inovação que contribuíram com esta investigação. 
1. Marinho VT, Costa ICP, de Andrade CG, dos Santos KFO, Fernandes MGM, de Brito FM. A percepção de idosos acerca do envelhecimento ativo. Rev enferm UFPE on line. [Internet] 2016;10(5) [acesso em 04 nov 2016]. Disponível: http://www.revista.ufpe.br/revistaenfermagem/index.php/revista/article/viewFile/9245/pdf_10121.

2. da Costa LJA, de Oliveira EA, Barros SEB, de Sousa JPR. Estudo comparativo dos parâmetros antropométricos e pulmonares entre idosas ativas e sedentárias. Rev. Geriatr. Gerontol. [Internet] 2014;8(4) [acesso em 04 nov 2016]. Disponível: http://ggaging.com/details/79/pt-BR/a-comparative-study-of-pulmonary-and-anthropometricparameters-between-physically-active-elderly-women-and-sedentary-women.

3. Zazá DC, Menzel HK, Chagas MH. Efeito do step-training no aumento da força muscular em mulheres idosas saudáveis. Rev. bras. cineantropom. desempenho hum. [Internet] 2010;12(3) [acesso em 04 nov 2016]. Disponível: http://dx.doi.org/10.5007/1980-0037.2010v12n3p164.

4. Vieira ER, Tappen R, Gropper SS, Severi MT, Engstrom G, de Oliveira MR, et al. Changes on walking during street crossing situations and on dorsiflexion strength of older Caribbean Americans after an exercise program: a pilot study. J Aging Phys Acti. [Internet] 2017 [acesso em 30 mar 2017]. Disponível: http://dx.doi.org/10.1123/ japa.2016-0231.

5. Müller DVK, Tavares GMS, Gottlieb MGV, Schneider RH. Avaliação do equilíbrio corporal e da força isocinética de flexores e extensores de joelho de um idoso sarcopênico, diabético com deficiência visual total: estudo de caso comparativo. Rev. Aten. Saúde. [Internet] 2016;14(48) [acesso em 30 mar 2017]. Disponível: http://seer.uscs. edu.br/index.php/revista_ciencias_saude/article/view/3616/pdf.

6. Clark BC, Manini TM. Functional consequences of sarcopenia and dynapenia in the elderly. Curr Opin Clin Nutr Metab Care. [Internet] 2010;13(3) [acesso em 04 nov 2016]. Disponível: http://dx.doi.org/10.1097/ MCO.0b013e328337819e.

7. Pereira A, Izquierdo M, Silva AJ, Costa AM, Bastos E, González-Badillo JJ, et al. Effects of high-speed power training on functional capacity and muscle performance in older women. Exp Gerontol. [Internet] 2012;47(3) [acesso em 04 nov 2016]. Disponível: http://dx.doi.org/10.1016/j.exger.2011.12.010.

8. Rikli RE, Jones CJ. Senior Fitness Test Manual. Champaign (IL): Human kinetics; 2001.

9. Schoenell M, Bgeginski R, Kruel L. Efeitos do treinamento em meio aquático no consumo de oxigênio máximo de idosos: revisão sistemática com metanálise de ensaios clínicos randomizados. Rev Bras Ativ Fis Saúde. [Internet] 2016;21(6) [acesso em 04 nov 2016]. Disponível: http://dx.doi.org/10.12820/RBAFS.V.21N6P525-533.

10. Castro F, Castro L, Carvalho L, Sbardelott Y, Sousa J, Martinelli P. Hidroterapia no tratamento da Osteoartrite de quadril: revisão bibliográfica. DêCiência em Foco. [Internet] 2017;1(1) [acesso em 30 mar 2017]. Disponível: http://revistas.uninorteac.com.br/index.php/DeCienciaemFoco0/article/view/21.

11. de Medeiros JJ, Brito MVG, Perracini MR, de Araújo FB, Santos AD. Aplicabilidade de hidroginástica e musculação em pessoas idosas da comunidade. Rev. Interf. [Internet] 2014;12(6) [acesso em 30 mar 2017]. Disponível: http://interfaces.leaosampaio.edu.br/index.php/revista-interfaces/article/view/132.

12. da Silva RS, do Nascimento Júnior JRA, Vieira LF, de Oliveira DV. Qualidade de vida e capacidade funcional de idosas praticantes de hidroginástica no município de Sarandi/PR. Rev. Bras. Qual. Vida. [Internet] 2016;8(1) [acesso em 30 mar 2017]. Disponível: http://dx.doi.org/10.3895/rbqv.v8n1.3670.

13. Bitencourt E, Helegda L, Almeida G, Schlindwein-Zanini R, Liposcki D. Aplicação de teste para membros inferiores em idosos institucionalizados. FIEP BULLETIN. [Internet] 2011;81(2) [acesso em 04 nov 2016]. Disponível: http://www.fiepbulletin.net/index.php/fiepbulletin/article/view/340.

14. Antes DL, Katzer JI, Corazza ST. Coordenação motora fina e propriocepção de idosas praticantes de hidroginástica. RCEH. [Internet] 2008;5(2) [acesso em 04 nov 2016]. Disponível: http://dx.doi.org/10.5335/ rbceh.2012.109.

15. Nicolai S, Benzinger P, Skelton DA, Aminian K, Becker C, Lindemann U. Day-to-day variability of physical activity of older adults living in the community. J Agin Phys Act. [Internet] 2010;18(1) [acesso em 04 nov 2016]. Disponível: https://www.ncbi.nlm.nih.gov/pubmed/20181995. 
16. Aboarrage N. Treinamento de força na água: uma estratégia de observação e abordagem pedagógica. São Paulo: Phorte; 2008.

17. Seemann T, Schmitt CW, Guimarães ACA, Korn S, Simas JPN, Souza MC, et al. Treinabilidade e reversibilidade na aptidão física de idosas que participantes de programa de intervenção. Rev bras. geriatr. gerontol. [Internet] 2016;19(1) [acesso em 04 nov 2016]. Disponível: http://dx.doi.org/10.1590/1809-9823.2016.15099.

18. Ferretti A, Monaco E, Ponzo A, Basiglini L, lorio R, Caperna L, et al. Combined intra-articular and extra-articular reconstruction in anterior cruciate ligament-deficient knee: 25 years later. Arthroscopy. [Internet] 2016;32(10) [acesso em 30 mar 2017]. Disponível: http://doi.org/10.1016/j.arthro.2016.02.006.

19. Rikli R, Jones J. Sênior Fitness Test Manual. Human Kinetics; 2008.

20. Rodrigues PAF, Bustamante CGA, Fonseca-Junior SJ, Fernandes Filho J. Força isométrica, composição corporal e autonomia funcional de idosos. Rev. Uniabeu. [Internet] 2016;9(23) [acesso em 30 mar 2017]. Disponível: http:// www.uniabeu.edu.br/publica/index.php/RU/article/view/2519.

21. Rebelatto JR, Calvo JI, Orejuela JR, Portillo JC. Influência de um programa de atividade física de longa duração sobre a força muscular manual e a flexibilidade corporal de mulheres idosas. Rev. bras. fisioter. [Internet] 2006;10(1) [acesso em 30 mar 2017]. Disponível: http://dx.doi.org/10.1590/S1413-35552006000100017.

22. Lima RM, Ferreira CES, Bezerra LMA, Rabelo HT, da Silva Junior C, dos Santos EP, et al. Estudo de associação entre força muscular e massa magra em mulheres idosas. Rev. Bras. Ciênc. Esporte. [Internet] 2012;34(4) [acesso em 04 nov 2016]. Disponível: http://dx.doi.org/10.1590/S0101-32892012000400013.

23. Dorosty A, Arero G, Chamar M, Tavakoli S. Prevalence of sarcopenia and its association with socioeconomic status among the elderly in Tehran. Ethiop J Health Sci. [Internet] 2016;26(4) [acesso em 31 mar 2017]. Disponível: http://www.ajol.info/index.php/ejhs/article/view/139588.

24. Wang E, Nyberg SK, Hoff J, Zhao J, Leivseth G, Torhaug T, et al. Impact of maximal strength training on work efficiency and muscle fiber type in the elderly: Implications for physical function and fall prevention. Exp Gerontol. [Internet] 2017;(91) [acesso em 31 mar 2017]. Disponível: http://doi.org/10.1016/j.exger.2017.02.071.

25. de Aguiar JB, Gurgel LA. Investigação dos efeitos da hidroginástica sobre a qualidade de vida, a força de membros inferiores e a flexibilidade de idosas: um estudo no Serviço Social do Comércio - Fortaleza. Rev. bras. educ. fís. Esporte. [Internet] 2009;23(4) [acesso em 04 nov 2016]. Disponível: http://dx.doi.org/10.1590/S180755092009000400003.

26. dos Santos AA. Flexibilidade em praticantes de hidroginástica. Rev Bras Presc Fisiolol Exerc. [Internet] 2010;4(21) [acesso em 04 nov 2016]. Disponível: http://www.rbpfex.com.br/index.php/rbpfex/article/view/253/254.

27. de Almeida APPV, Veras RP, Doimo LA. Avaliação do equilíbrio estático e dinâmico de idosas praticantes de hidroginástica e ginástica. Rev. bras. cineantropom. desempenho hum. [Internet] 2010;12(1) [acesso em 04 nov 2016]. Disponível: http://dx.doi.org/10.5007/1980-0037.2010v12n1p55.

28. Cardoso AS, Mazo GZ, Balbé GP. Níveis de força em mulheres idosas praticantes de hidroginástica: um estudo de dois anos. Motriz rev. educ. fís. (Impr.). [Internet] 2010;16(1) [acesso em 04 nov 2016]. Disponível: http://www.periodicos.rc.biblioteca.unesp.br/index.php/motriz/article/view/2852/2769.

29. Araújo RCM, Barbosa MTS. Análise comparativa da força muscular de mulheres idosas praticantes de ginástica e hidroginástica. MOVIMENTUM - Revista Digital de Educação Física. [Internet] 2007;2(1) [acesso em 04 nov 2016]. Disponível: http://www.unilestemg.br/movimentum/Artigos_V2N1_em_pdf/movimentum_v2_n1_araujo_ rita.pdf. 